\title{
FORUM
}

\section{Insect Drift and the Case of Mayrinia curvidens (Mayr) (Hemiptera: Pentatomidae) Drift on the Southern Atlantic Coast of Brazil}

\author{
Sonia M.N. LaZZari ${ }^{1}$, Antônio R. PanizZi² and Jocélia Grazia ${ }^{3}$ \\ ${ }^{1}$ Depto. Zoologia, Univ. Federal do Paraná, C. postal 19020, 81531-980, Curitiba, PR, lazzari@ufpr.br \\ Contribution DZ/UFPR 1690 \\ ${ }^{2}$ Lab. Bioecologia de Percevejos, Embrapa Soja, C. postal 231,86001-970,Londrina, PR, panizzi@cnpso.embrapa.br \\ ${ }^{3}$ Depto. Zoologia, Univ.Federal do Rio Grande do Sul, Av. Bento Gonçalves 9.500, 91501-970 \\ PortoAlegre,RS, jocelia@ufrgs.br \\ Neotropical Entomology 37(2):109-117 (2008)
}

Deriva de Insetos e o Caso da Deriva de Mayrinia curvidens (Mayr) (Hemiptera: Pentatomidae) na Costa Atlântica Sul do Brasil

\begin{abstract}
RESUMO - A deriva de insetos nas margens de lagos e mares é um fenômeno relativamente comum, embora aparentemente não seja relatado na literatura com freqüência. Procedeu-se a uma revisão sobre a deriva de insetos com ênfase sobre os casos relatados para percevejos (Heteroptera), e especulou-se sobre as possíveis causas para explicar esse fenômeno. O caso impressionante da deriva de populações do pentatomídeo Mayrinia curvidens (Mayr) nas praias do oceano Atlântico no Sul do Brasil é relatado pela primeira vez. Essa deriva, observada previamente em menor intensidade em meados da década de 1970 (A.R. Panizzi, não-publicado), foi constatada novamente em janeiro de 2006 ao longo da costa do Oceano Atlântico no Paraná (latitude $25^{\circ} 45^{\prime} \mathrm{S}$ ), onde uma população estimada de 16 a 18 milhões de exemplares mortos foram encontrados formando uma faixa de pelo menos $15 \mathrm{~km}$ de extensão ao longo da praia. As circunstâncias que ocasionaram esse evento são analisadas em detalhe considerandose dados meteorológicos e o possível aumento das populações do percevejo em plantas hospedeiras cultivadas e não-cultivadas ao longo da costa do Paraná e de Santa Catarina.
\end{abstract}

PALAVRAS-CHAVE: Heteroptera, percevejo, condição atmosférica, vôo de insetos, dispersão, mar

\begin{abstract}
Insect drift on shore of lakes and seas is a relative common phenomenon although apparently not frequently reported in the literature. Here we review the worldwide occurrence of insect drift with emphasis on Heteroptera, and speculate on possible causes to explain such phenomenon. The dramatic drift of million of specimens of the pentatomid Mayrinia curvidens (Mayr) on the shore of the southern coast of the Atlantic ocean in Brazil is reported for the first time. This drift, previously observed to occur in the mid 70's on the coast of Paraná state with minor intensity (A.R. Panizzi, unpublished) was again observed on January 2006 along the Atlantic coast of Paraná (latitude $25^{\circ} 45^{\prime} \mathrm{S}$ ), where an estimated population of 16 to 18 million of dead specimens of the bug were observed forming a windrow for at least $15 \mathrm{~km}$ along the ocean shore. The circumstances of such event are analyzed in detail considering meteorological data and the possible build up of populations of the bug on cultivated and non-cultivated host plants along the coast of the states of Paraná and Santa Catarina.
\end{abstract}

KEY WORDS: Heteroptera, stink bug, atmospheric condition, insect flight, dispersion, sea

The objectives of this paper are to review the literature on the occurrence of insect drift and possible causes and or processes involved in these events. Also, to record an event of insect drift that occurred in a beach in southern Brazil. The occurrence of terrestrial insects in ocean beach drifts forming a windrow for several kilometers along the shore is a rare phenomenon. A brief literature review follows in order to present similar reports on insect drifts worldwide, especially Heteroptera, and also some theories and mechanisms involved with insect mass flights, dispersion, and migration that could possibly explain the phenomenon.

\section{Insects on Lake and Ocean Beach Drifts}

Insects have been found in lake and ocean beach drift, sometimes in great numbers and it has been suggested that they are blown out over or washed into the water during 
storms (Needham 1900). They are possibly attracted to sunlight reflecting off the water during a clear day and, sometimes, strong off-shore winds are responsible for the presence of the insects in the water (Parshley 1917), or for them to land in the water during spring and fall flights (Myers 1926).

One of the earliest records of insect drifts was of the striped ground cricket, Nemobius fasciatus DeGeer (Orthoptera: Gryllidae), in 1899, and of beetles mostly of a single species in 1904 with a great accumulation on the shores of Lake Michigan (Needham 1900, 1904). Both events occurred on a bright summer day and the insects were brought ashore by gentle winds.

In 1915, Torre Bueno published extensive records of Heteroptera drifts on ocean (49 species) and lake shores (22 species). He mentions that these heteropteran flights are not nuptial in character and seemed to be unrelated to any fixed atmospheric conditions. He noted that these drifts occurred mainly during elevated daytime ambient temperature and the winds were of a particular direction. Myers (1926) states that insect beach drifts extending for miles along the beach is a matter for legitimate speculation. He studied collections of Hemiptera from beach drifts on the Massachusetts coast and added some more species to those reported by Torre Bueno (1915) and Parshley (1917). The hemipteran family with the largest number of species collected by Myers was Pentatomidae. He mentions that certain weather conditions were common on the dates when the events were noticed, such as warm and bright sunshine that were favorable to extensive flights. He concluded that the occurrence of large numbers of insects in ocean drifts, Heteroptera in particular, was related with spring and autumn flights, more than Parshley (Parshley 1917) believed.

Needham (1917) registered the conditions of wind, waves and weather related to insect drifts on the shores of Lake Michigan. Coleoptera were the most abundant insects in the drift, followed by Hemiptera. Of the Hemiptera, the most abundant were aphids, but they were minute and in a bad state of preservation, and for these reasons they were not considered in his studies. More than half of the large hemipterans were Pentatomidae. He noticed that the unusual deposits of insects were unrelated to storms, and linked these drifts to off-shore storm winds that blew insect swarms in unusual abundance into shore drifts. He stated that the insect emergence period was the most significant element because the wind and waves gather the resulting insects into drifts.

Unusual mass flights of Heteroptera have also been recorded inland, such as those of the Pentatomidae Thyanta custator (Fabricius) in the North central region of the United States from 1937 to 1939. T. custator was recorded by Severin (1937) at Sioux Falls, South Dakota in 1936 and by Ainslie (1938) at Sioux City, Iowa on October 8, 1937. Both mention that these pentatomids were a nuisance, swarming about the lights and entering stores and residences, besides the production of an unpleasant odor from crushed insects.

On October 14, 1938, Wilbur (1939) reported a mass flight of T. custator that was attracted to the floodlights of football fields and caused extreme annoyance, due to their mass and their obnoxious odor. The swarms occurred for one night, following a line drawn diagonally from the southwest corner to the northeast corner of Kansas. The flight followed the warmest two- week period ever recorded in Kansas during October. Southerly winds prevailed and the meeting of a cooler current aloft from the northeast and a warmer current from the south caused the bugs to descend along the mentioned line. It is not known whether these flights represented an extensive migration or whether the insects originated in the localities in which they were observed swarming about the lights. The species $T$. custator was the most common pentatomid in Kansas, occurring throughout the growing season on wheat and on weeds, but there were no indications of any unusual abundance of this bug prior to the referred flights.

Hardy \& Milne (1937), using kite nets flown from ship masts, detected a very large population of 'aerial plankton' drifting across the North Sea. The species collected, mainly Aphididae and several families of Diptera were regarded as too small and weak in flight to be true migrants. The insects were taken both during day and night, even in rain or fog. One year late, these same authors (Hardy \& Milne 1938) sampled aerial drifts of insects over the land at different heights in Tetney, North Lincolnshire, UK. They observed again that the aerial plankton was composed essentially by small lightbodied insects with weak flight, but with a relatively large wing surface compared with body mass.

Freeman (1938) presented the results of a series of collections taken for two years the same location studied by Hardy \& Milne (1938). Although $75 \%$ of the total insects collected in the aerial fauna were below $33 \mathrm{~m}$, most Diptera and Hemiptera were above this level. Aphididae was the dominant family at all heights. The greatest number and variety of insects occurred during June and September, during peak breeding and dispersal. The greatest numbers of all insects occurred at relative humidity below $59 \%$, at a surface wind velocity below $9 \mathrm{mph}$, and at temperatures above $18^{\circ} \mathrm{C}$. Winds exercised most control on collection and play an important roll in insect dispersal. Hardy \& Cheng (1986) continued that survey started by Hardy \& Milne (1938) and concluded that the insects may be found in drifts $160 \mathrm{~km}$ from the mainland, including many important aphid pest species. Understanding such drifts may be of value to explain the spread of insect pests over the land and colonization of islands in the Great Britain and elsewhere.

McPherson (1982) described the Pentatomoidea of Illinois and North America, including a list of northeastern species that have been collected in ocean and lake beach drifts. He mentioned that although pentatomoids are diurnal, they may be attracted by electric lights and black lights.

By aerial sampling and radar detection it has been shown that many species of insects disperse in the atmosphere by day and night over land and over the oceans. The ensemble of these passively drifting insects and other small organisms is called 'aerial plankton' (Drake \& Farrow 1989). According to radar observations of Russell \& Wilson (2001) diurnal aerial plankton is composed of small, weak flying insects that drift with the wind. Russell \& Wilson (2001) concluded that densities of aerial plankton become concentrated on coastlines and apparently avoid drifting out over the ocean, suggesting that insects may actively trace wind in the vicinity of coastlines unless they are too small, i.e., Diptera and 
Hemiptera/Homoptera, which predominate in collections obtained from the sea surface.

Insects probably fly by the coast in response to a shift in the perceived visual grain from the ground to the water pattern by optical images across the retina, as indicated by Johnson (1969). Their behavior includes active downward flight to enter zones where wind speeds decrease and flight control is improved. Russell \& Wilson (2001) concluded that coastal insect concentrations may drop out of aerial plankton, resulting in temporary or even permanent increases in insect biomass and diversity in terrestrial coastline habitats. Drake (1984) mentions that insects migrating at night may encounter low level wind jets associated with nocturnal temperature inversions which may transport them for long distances at speeds of over $100 \mathrm{kmh}^{-1}$.

Drake et al. (1981) used radar to observe insect flight activity at a coastal locality in north-western Tasmania. Insect movements from the Australian mainland were associated with warm airflows that often occur ahead of a cold front. Massive take-offs of migratory moths, were detected, shortly after sunset and always in an approximate downwind direction. A second take-off of small insects may take place shortly before dawn. Insect movement was detected both during day and night. The use of radar, traps, and filming allowed the determination of not only the relative size and number of the insects, but also the direction or source and the speed of the flights. Migratory moth flight speed was between 12 and 18 $\mathrm{m} / \mathrm{sec}$, and flights ranged from $200 \mathrm{~km}$ to $230 \mathrm{~km}$ from the mainland to some of the islands in the Bass Strait.

As reviewed by Gatehouse (1997), ascending insect flights usually involve positive phototaxis and takeoff by diurnal wind-borne insects may be due to endogenous factors, patterns of emergence and completion of teneral period, and environmental factors (mainly temperature, wind, and rainfall). In sunny conditions, adequate convective up currents will occur by late morning when radar shows peaks of flight activity (Russell \& Wilson 2001). Nocturnal flights initiated shortly after dusk are influenced by temperature, and are inhibited by low temperatures associated with the passage of cold fronts. Takeoff is generally followed by a rapid ascent, with flight rates varying according the species.

Pathak (1998) and Pathak et al. (1999) collected insects during a cruise in the Arabian Sea. Air borne insects were trapped with conical nylon nets and the flotsam collections were made using standard zooplankton nets. They found large numbers of terrestrial insects over and in the oceanic waters, most of them small ( 0.6 to $3 \mathrm{~mm}$ in length) and weak fliers, carried up with thermal currents and then across the oceans with the help of wind currents. The passage of these insects over the Arabian Ocean was almost passive and a large proportion of them may have fallen in the ocean waters and contributed to the oceanic biomass. Hymenoptera, Hemiptera, and Diptera were the dominant orders, including large body size species, what is quite intriguing. This kind of data sheds new light on zoogeographic distribution of essentially terrestrial insects and, corroborated by meteorological data, may indicate a pattern of dispersal and colonization of new areas. The authors suggest a possible threshold weight beyond which airborne material tends to descend with increasing distance. The absence of collection of larger insects at distances exceeding $100 \mathrm{~km}$ from the nearest land mass appears to support this suggestion.

\section{Aggregations and Dispersal}

According to Brues (1926), swarms or aggregations of insects may be due to several quite distinct causes. These include large colonies of social insects due to social life and a high reproductive capacity; nuptial flights of ants and termites; gregarious populations preparing for hibernation; and movements towards artificial light. Insect drift may also indicate widespread dispersal or migration somehow related to air currents. However, increased insect abundance may be correlated with abundant food supply as observed for insect pests on various cultivated plants.

Dispersal in its broadest sense means movement away from the birthplace, whereas migration involves movement in a periodically and geographically predictable way, occurring either just once or many times. Migration may be induced or be coincident with the necessity for a food supply larger than the one available without migration (Brues 1926). Holland et al. (2006) state that by spreading their breeding efforts both spatially and temporally, insects are seeking areas and conditions that may be amenable for future reproduction. The authors mention that, as a rule, insects do not make a roundtrip journey to the area from which they departed. Insects are often facultative migrants that respond to changes in habitat quality, availability and crowding.

Johnson (1969) mentions that migration or adaptive dispersal is often associated with high population densities to ensure survival and reproduction. This author also discusses that emigration may be an activity that, to certain degree, is dependent on density as described for a species of Miridae. When the population of mirid adults doubled in a certain year due to the poor state of the host plant and high temperature, a great mass flight occurred. Johnson continues mentioning that many insect populations build up in dense crowds prior to migration as a result either from a mass emergence synchronized by rising temperature or by concentration into a zone of convergence during migration. He considers that both long-range and medium-range migrations must be seen in the context of the meteorological condition over a very wide area, considering movement and development of largescale pressure systems. It is more likely that the insects would make flights for a limited period in the warm section of a depression zone, and as the warm front passes over an area, insects become more active, are taken aloft and transported in warm winds. If it happens in the advance of the oncoming cold sector they may be taken up on the convection associated with the front and cease to fly as the air becomes colder or rain falls and deposit them. Understanding the weather systems and fronts helps to explain why migrants often appear just before or just after a storm. Johnson (1969) continues mentioning that there are two major factors which might contribute to the concentration of insects along coastlines: first, flying low over a land-water junction helps them to maintain a preferred retinal velocity of ground images and second, and more likely, is the effect of convergent winds along seashores. Flying insects may be blown out to sea on 
general off-shore winds and later brought back at a lower altitude to become concentrated along the shore, or slightly inland, according to the large scale weather at the time.

Other studies confirm that wind plays a significant role in insect dispersal flights, not only associated with migrations, but also with a wide range of insect species not classified as regular migrants. Most of them, including dayflying heteropterans and several small insects like aphids and microlepidopterans migrate predominantly downwind. However, some species migrate upwind according to the neurophysiology of the species or when following pheromone paths or odors of host plants or food in trivial flights. Drake \& Farrow $(1988,1989)$ also consider that atmospheric conditions, especially wind convergence in the ocean coast, exert a great influence on insect migration. They present some examples that illustrate a variety of connections between atmospheric convergence and terrestrial ecology. They state that stationary convergence zones are more likely to produce surface aggregations than mobile ones, and persistent or recurring convergence is more likely to carry migrants to rainfall than isolate wind systems. However, to establish the significance of atmospheric convergence for a particular species, many conditions are required. Among them is the occurrence of convergence wind fields and convergenceproduced rainfall which is the key factor that causes localized insect outbreaks at convergence zones. Besides these atmospheric conditions, a concentration of immigrant populations on the ground is required. They conclude that aerial concentrations of insects produce aggregation on the ground, and that convergence effects have long-term significance for populations rather than just producing temporary fluctuations. Thus, convergence or atmospheric movement is simply a means of colonizing distant habitats, i.e. of migrating in the ecological sense.

Leston (1957) calculated that the Spread Potential Rank for Pentatomidae among 15 heteropteran groups is 3, which is the likelihood that a member of a particular taxon would occur on an island. He partially explained that on the basis of the number of species, then, merely by chance, some groups are more likely to find and colonize islands. Schaefer (2004) mentions that the Leston's Spread Potential is not influenced only by the taxon size, but also it is correlated with body size (as a measure of vagility) and with host specificity. All correlations would be analyzed together to explain the spread potential of a taxon. The higher the vagility and taxon size, the less important host specificity; and vice versa. And as suggested by the case of the Coreidae collected by Pathak et al. (1999) which was the most abundant heteropteran family trapped in the Arabian Sea, the larger the taxon, the less important is vagility.

Drake \& Gatehouse (1995) present a comprehensive overview on insect migration, stating that migration is a key process in the population dynamics of many insect species, including some agricultural pests. It may be obligatory but more usually occurs facultatively in response to environmental cues. Current understanding of the ecological, behavioral, physiological, and genetic basis of insect migration are reviewed for species in different geographic regions and the role of regional weather and climate. It is also addressed the application of the accumulated knowledge to operational pest forecasting. A conceptual model of insect migration is proposed by Drake et al. (1995) incorporating both a spatial and a genetic dimension.

A recent comprehensive study on the theme migration and dispersal (Holland et al. 2006) concluded that insect migration is an important phenomenon for colonization of new habitats and pest dispersal, but still poorly understood because of the many factors involved in this complex insect activity and because the current tracking system is still unsuitable for such small organisms.

\section{The case of Mayrinia curvidens}

In January 2006, after a storm, millions of specimens of a single pentatomid species, M. curvidens, were found dead on the shore of Praia das Gaivotas, a sand beach at the east coast of the state of Paraná in southern Brazil (latitude $25^{\circ} 45^{\prime} \mathrm{S}$ ) (Fig. 1). This is apparently the first record of an insect drift on an ocean shore in Brazil and the first published record of such $M$. curvidens mortality worldwide. Since the occurrence of $M$. curvidens is very scattered on a few crops in Brazil, it does not have a pest status, however, it displayed its high biotic potential in this particular event.

The pentatomid M. curvidens was first described in 1864 as Loxa curvidens Mayr, and later transferred to the genus Mayrinia by Horvath (1925). The genus was further revised by Grazia-Vieira (1972), who included redescriptions with figures, measurements and collection data. The distribution of M. curvidens is Neotropical and it has been recorded in Brazil, mainly in the southeastern and southern states; as well as in Bolivia, Paraguay, and Argentina. References as to $M$. curvidens occurrence on host plants are scarce, but include Solanaceae (Grazia-Vieira 1972), soybean (Panizzi \& Smith 1976), rice and soybean (Link \& Grazia 1987), and recently on wheat (P.R.V.S. Pereira, personal communication). It is interesting to note that its record on soybean in Paraná State in the soybean season of 1973/1974 (Panizzi \& Smith 1976) meets the minor drift event of $M$. curvidens on the beach of Paraná State in the summer of 1974 (A.R. Panizzi, personal observation). The insect was recently observed in low numbers on rice before harvest, and on Aeschynomene denticulata Rudd (Fabaceae), a weed in rice fields in the state of Santa Catarina (D. Link, personal communication). During autumn 2005, M. curvidens was the most abundant species collected using the beat tray method (63\% of total hemipteran species) in a conservation area in the northwestern region of Rio Grande do Sul State (Schmidt $\&$ Barcellos 2007). However, there were no complaints from farmers of infestations of this species on cultivated soybean or wheat in areas adjacent to the state park surveyed.

The mass mortality of $M$. curvidens that resulted in a large ocean beach drift occurred for just one day, January 27,2006 . The event was photographed and specimens were collected and identified. A few individuals were measured and a tentative estimation of the number of individuals in the drift was made. Meteorological data was obtained from the Centro de Estudos do Mar da Universidade Federal do Paraná weather station, in Pontal do Paraná, about $20 \mathrm{~km}$ from the site of the drift. A global positioning system (GPS 


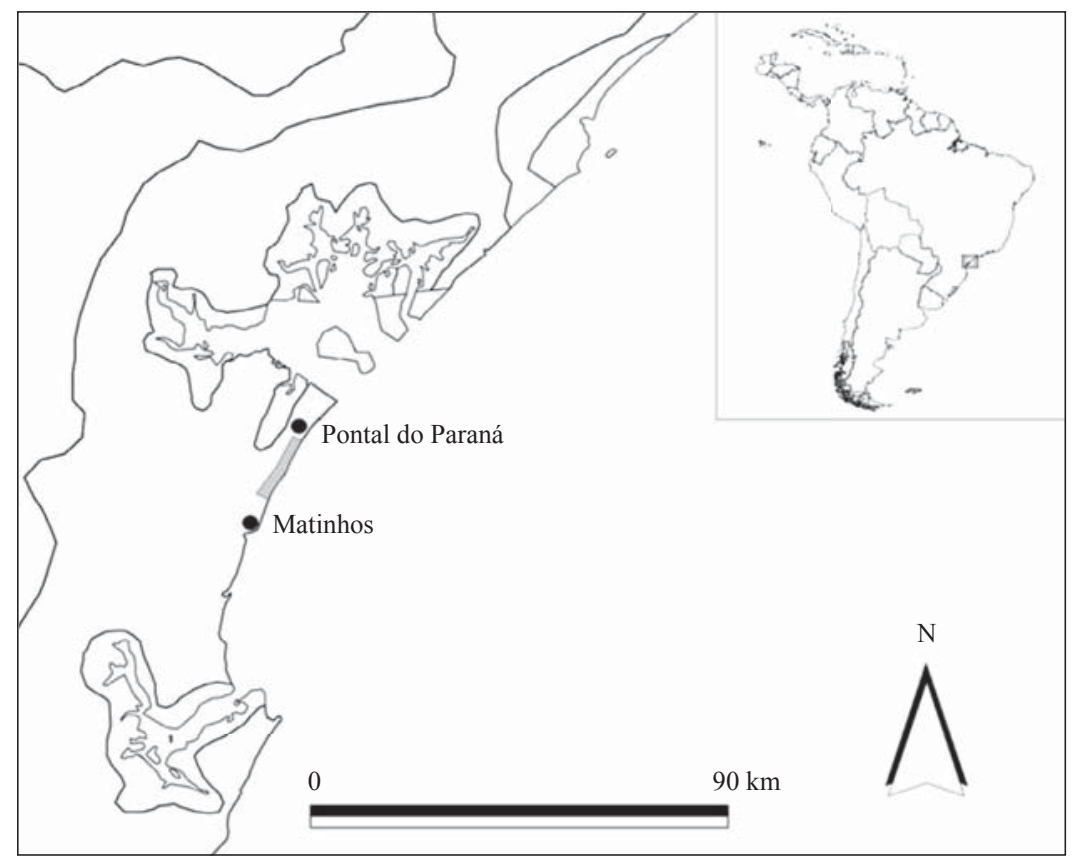

Fig. 1. Location where the drift of M. curvidens occurred in the coast of Paraná State, Brazil, during January 2006. The shaded area between Praia de Leste (Pontal do Paraná) and Matinhos indicates the approximately $15 \mathrm{~km}$ extension of the event by the shore of the Atlantic ocean.

- Garmin \& Trex Personal navigator 12 channels, Garmin International, Inc., KS) was used to define the coordinates ( $8 \mathrm{~m}$ precision) between the two points (about $2 \mathrm{~km}$ apart), where the insects accumulated on the shore. This location was defined as from $25^{\circ} 42^{\prime} 36.8^{\prime \prime} \mathrm{S}, 48^{\circ} 28^{\prime} 36.1^{\prime \prime} \mathrm{W}$ to $25^{\circ} 44^{\prime} 55.5^{\prime}$ " S, $48^{\circ} 29^{\prime} 57.8^{\prime \prime} \mathrm{W}$.

The drift of dead specimens of $M$. curvidens washed up on shore stretched for about $15 \mathrm{~km}$ and averaged $30 \mathrm{~cm}$ in width, piling up in some places, but scattered in others. A rough number of 16 to 18 million insects was estimated by counting the specimens from the pictures that were more representative of the drift, and extrapolated to the approximated area where the insects were deposited. It is a very conservative estimate because no sampling method was applied at the moment of the event for a more precise counting.

Figs. 2 to 7 show a succession of pictures of the event. The dark drift line extending along the beach was composed exclusively by $M$. curvidens, except for some debris and for very few scattered other insects, including some Coccinellidae (Coleoptera), Membracidae (Hemiptera), a few moths (Lepidoptera), flies (Diptera), and hymenopterans (Hymenoptera). Seagulls were observed banqueting on the stink bugs. The drifts were removed mechanically beginning on January 28, 2006 because of the large amount of insects, the humeral spines that hurt people's feet, and the obnoxious odor of the decaying carcasses. Fig. 8 shows a female specimen of $M$. curvidens. Both males and females are bright green with conspicuous black humeral spines pointed forward. Dorsum of abdomen is red, visible when wings are spread out. There is a broad longitudinal yellow stripe ventrally on the middle of thorax and abdomen.
A random sample composed by 65 males and 79 females of $M$. curvidens was taken, and the body length and humeral width (between the bases of the humeral spines) of these specimens were measured. Females were very similar to the males in appearance, but a little larger in size. The males averaged (mean $\pm \mathrm{SD}) 11.0 \mathrm{~mm} \pm 0.5451(10.0-12.3 \mathrm{~mm}$; mode $=10.6 \mathrm{~mm}$ ) for the body length by $5.7 \mathrm{~mm} \pm 0.2645$ (4.9-6.2 mm; mode $=5.8 \mathrm{~mm})$ wide; whereas the females averaged $12.8 \mathrm{~mm} \pm 0.4070(11.8-13.8 \mathrm{~mm} ; \operatorname{mode}=12.9 \mathrm{~mm})$ in length by $6.3 \mathrm{~mm} \pm 0.2677(5.3-7.1 \mathrm{~mm}$; $\operatorname{mode}=6.5 \mathrm{~mm})$ wide. The average size of the insects collected was slightly larger for females and slightly smaller for males compared to the measurements presented by Grazia-Vieira (1972).

Fig. 9 shows a clear change in the direction and speed of the wind, blowing from the south-southeast and then $180^{\circ}$ south on January, 26, followed by heavy rain during the night, continuing in the early morning of January 27 (38.4 $\mathrm{mm}$ from midnight to 4:00 a.m.) (Fig. 9). Despite of being a month of historically high precipitation (average 284.9 $\mathrm{mm}$ ), January 2006 had very little rain prior to the night of January 26. The temperature from January 1 to January 26 averaged $26.6^{\circ} \mathrm{C}$ (Fig. 10), whereas the 30 years historical average temperature for January is $24.1^{\circ} \mathrm{C}$. There was no noticeable variation of the water temperature (about $24^{\circ} \mathrm{C}$ ); salinity was 32 ; average relative humidity of the air was 78.4 and radiation was also in the range of the historical data for January (Fig. 11). The insect population would have taken-off in the evening of January 26 lifted up by warm currents, but was caught and washed to the ground by the rain during the night. These masses of insects likely were washed ashore on the northern coast of the state of Santa Catarina. 

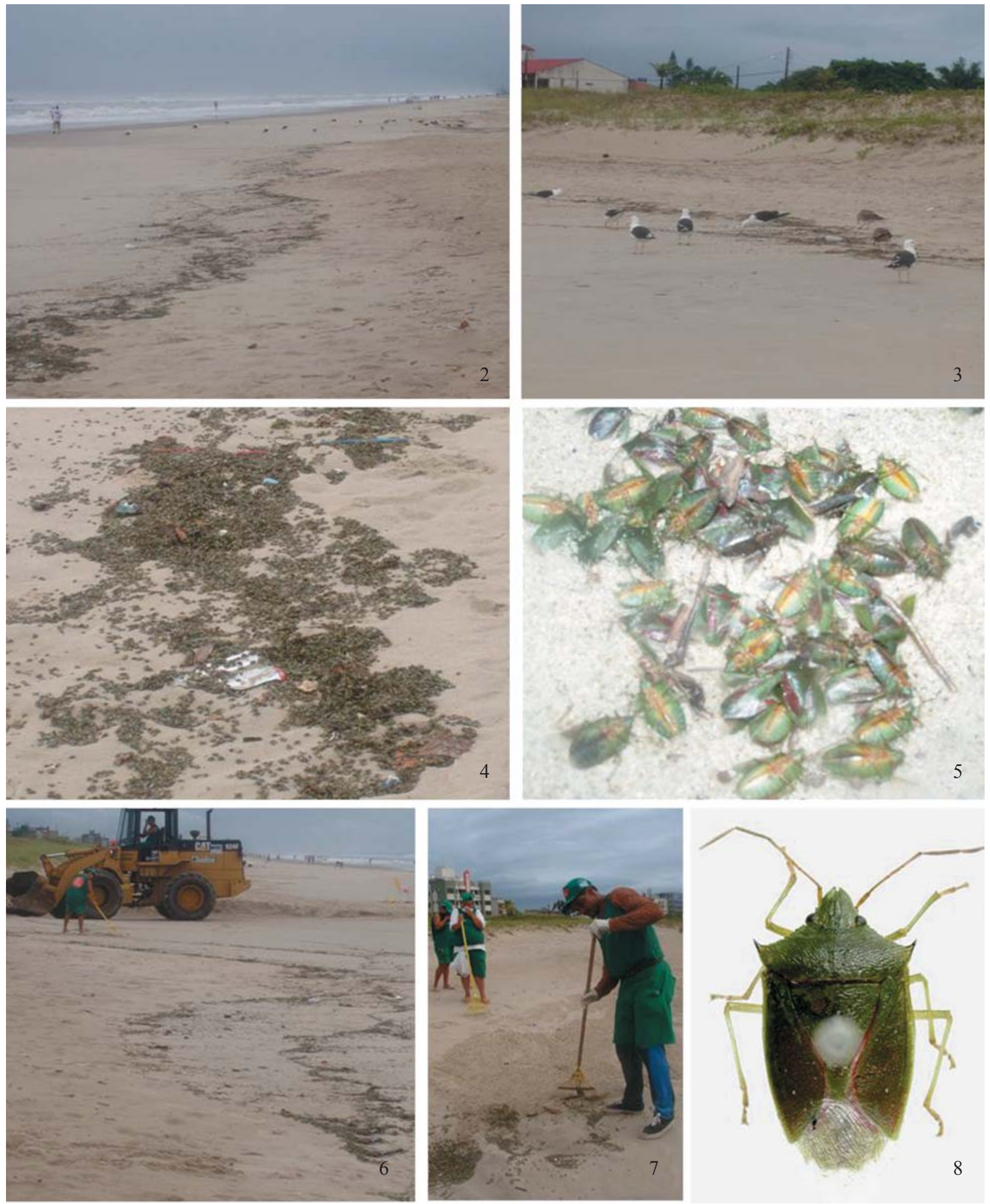

Figs. 2-8. Dead adults of M. curvidens on a beach drift in Praia das Gaivotas, Paraná State, Brazil, during January 2006. Figs. 2 and $4=$ Dead insects on the shore making a dark line along the beach for several kilometers; Fig. 3 = Seagulls feeding on the dead insects; Fig. $5=$ Details of the dead bugs on the beach, showing the typical broad longitudinal yellow stripe ventrally on the middle of thorax and abdomen; Figs. 6 and $7=$ Janitors collecting dead insects on the beach; Fig. $8=$ Adult female - dorsal view. 


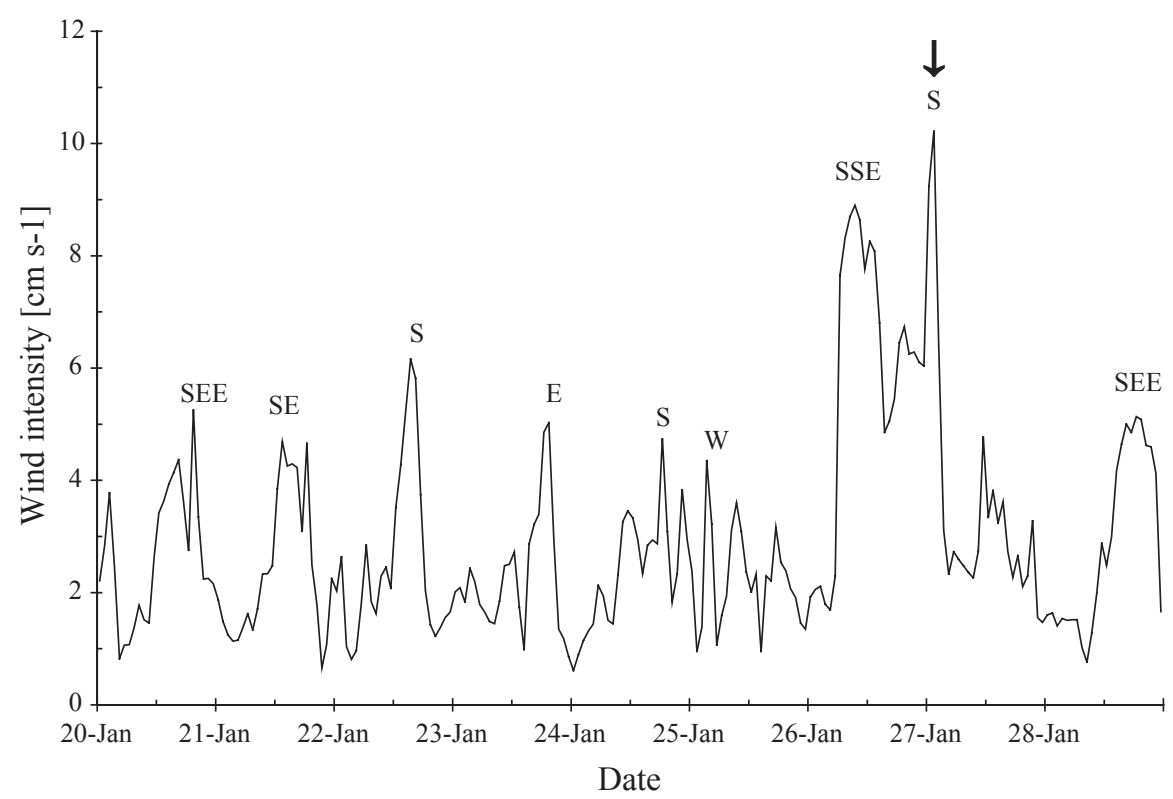

Fig. 9. Wind intensity and direction from Pontal do Paraná, southeastern coast of Brazil; January 2006. The arrow indicates the date when $M$. curvidens was washed ashore.

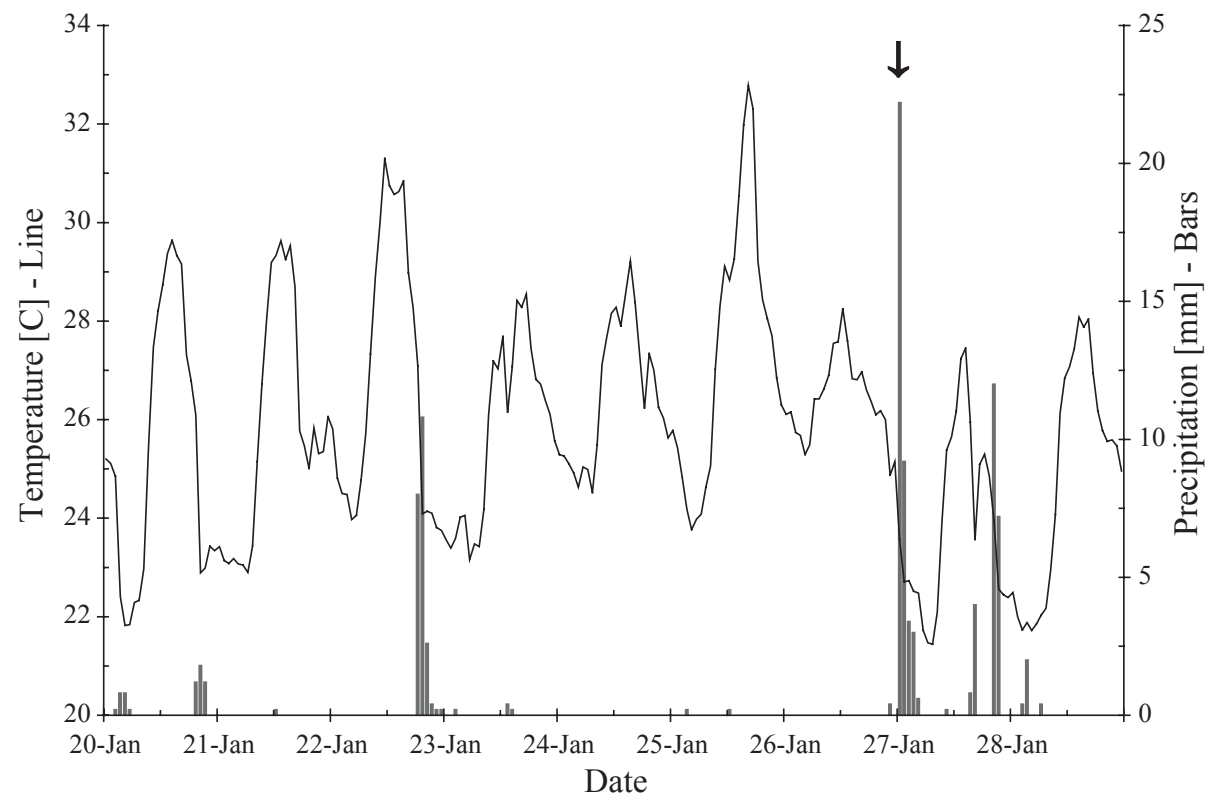

Fig. 10. Temperature and precipitation from Pontal do Paraná, southeastern coast of Brazil; January 2006. The arrow indicates the date when $M$. curvidens was washed ashore.

Many people from the area were inquired about this event. Fishermen and local residents reported that they never seen such an insect drift before. However, a similar, smaller event was observed in the same area in the summer of 1974, also involving $M$. curvidens. However, this event was not reported and no insects were collected (A.R. Panizzi, personal observation). Just before the January 26 beaching event, $M$. curvidens was reported to be entering into houses after being attracted by the lights in coastal cities south from the place where the drift occurred. Reports came from Barra Velha, on the coast of Santa Catarina state, at the end of November and beginning of December 2005 (M. Pereira, personal communication). About ten days before the drift, some 20 specimens were collected in a sixth floor apartment, entering through the open window facing the sea, attracted by light, in Itapema, Santa Catarina (J. Grazia, personal observation). 


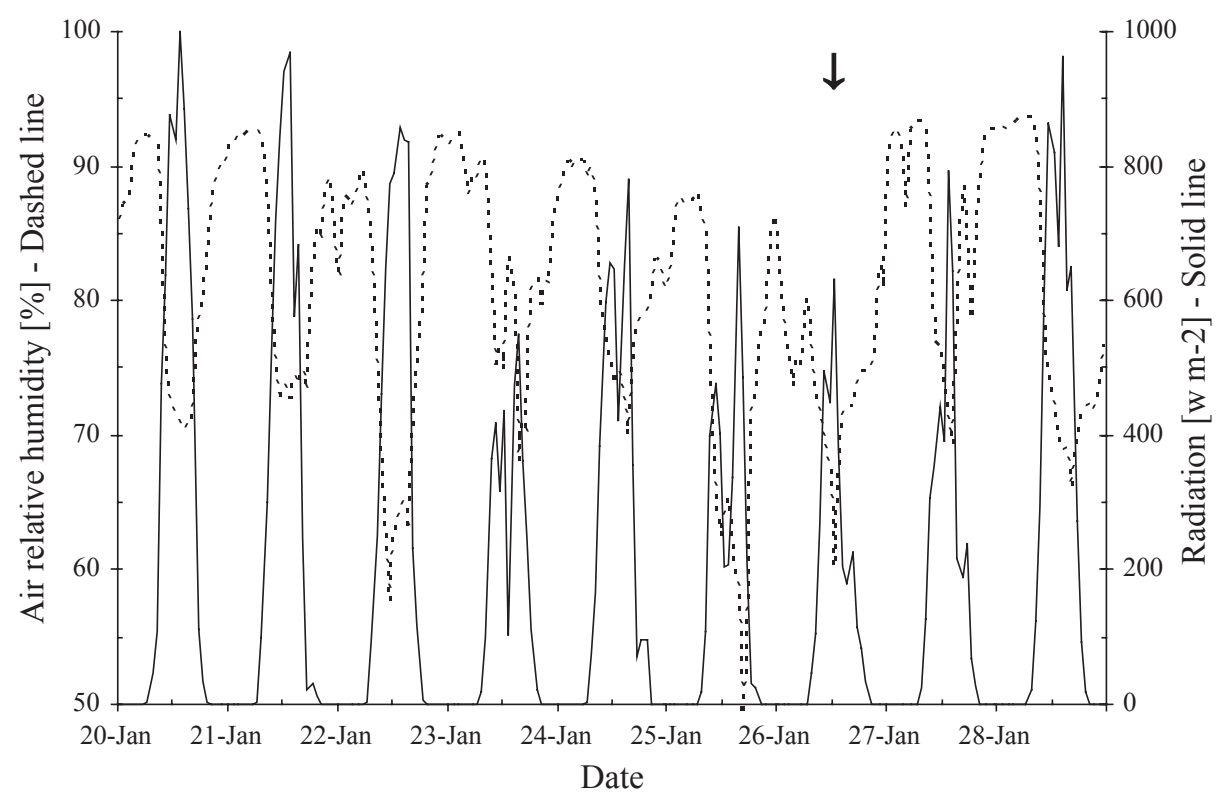

Fig. 11. Relative humidity and radiation from Pontal do Paraná, southeastern coast of Brazil; January 2006. The arrow indicates the date when M. curvidens was washed ashore.

After the event, in January and February, M. curvidens were observed flying around the lights in houses and restaurants in many coastal cities in Paraná and Santa Catarina states. About one month later, on February 26, masses of live M. curvidens averaging one individual per linear meter, were found again in Praia das Gaivotas, on the shore by the wave line (S.M.N. Lazzari, personal observation). In Pontal do Paraná, north of Gaivotas, people reported that they had to keep their south windows closed at night to avoid clouds of the stink bugs entering in the house by late January (M. Joaneau, personal communication). In other costal cities of Santa Catarina, mass flights of $M$. curvidens continue to occur in February in Itapoá Beach and in Governador Celso Ramos from January until late March (E.C. Santos, personal communication).

Almost one year before the great shore drift event, $M$. curvidens was observed infesting wheat plants in an open greenhouse of Embrapa Trigo in the town of Passo Fundo, in the state of Rio Grande do Sul. The infestation occurred during March and April 2005 on wheat plants grown on hydroponic trays for plant genetic experiments. The plants were at the stage 4 (Feekes and Large scale). The temperature inside the greenhouse was about $25^{\circ} \mathrm{C}$, and the infestation level reached 2 individuals $/ \mathrm{m}^{2}$. The degree of $M$. curvidens feeding damage resulted in the death of many plants and required insecticide applications to kill the infesting insects (P.R.V.S. Pereira, personal communication).

In January and February 2006, insect surveys in rice fields in São Bento Baixo, county of Nova Veneza, SC (28 42' 30"S, $49^{\circ} 2922^{\prime \prime} \mathrm{W}$ and $28^{\circ} 42^{\prime} 18^{\prime \prime} \mathrm{S}, 49^{\circ} 29^{\prime} 23^{\prime}$ ' W, altitude $35 \mathrm{~m}$ ), found that $M$. curvidens represented $19 \%$ of the Pentatomidae collected, and outnumbered some insect species commonly found on rice crops in this region. The area is characterized by fragments of the Atlantic Rain Forest, with hot and humid summers without a well defined dry season. M. curvidens has occurred in very low numbers in this area in previous seasons (L.A. Campos, personal communication).

The model proposed by Drake et al. (1995) and the factors affecting insect flight discussed by Johnson (1969) may explain the case of $M$. curvidens drifting. The depletion of resources caused by very high population density was a key factor triggering the insect dispersal; specific weather conditions, especially warm wind currents blew the insects off-shore and later the storm washed them ashore, what is corroborated by the meteorological data presented and by theories and facts presented in the literature.

\section{Conclusions}

This phenomenon, being categorized either as a migration or dispersal, was a response of $M$. curvidens to a spectacular overcrowding situation and it was a strategy to enable the species to find new food resources and breeding grounds. The development of such a huge population of the bug is still an enigma: M. curvidens is not a major pest of the cultivated host plants mentioned before (soybean, wheat, and rice), and not a common plant is known to host it in the wild. In addition, the bug is not commonly found in nature, which means it does not have a scattered distribution. Despite the storm that caught them over the ocean and washed them ashore, many of them survived and were dispersed, as observed a few days later, allowing the population to build up on new grounds. Therefore, it is important to look at this event using a holistic approach to be able to monitor and predict this species building up in new areas. Progress in research on this subject depends strongly on interdisciplinary approach, including adequate radar system and even molecular techniques to study insect flight and dispersal behaviors. 


\section{Acknowledgments}

We thank C. M. Smith, Department of Entomology, Kansas State University for reviewing the manuscript; C.W. Schaefer, Department of Ecology and Evolutionary Biology, University of Connecticut, for suggestions and providing some of the bibliography. We also thank Maurício A. Noernberg, from the Centro de Estudos do Mar - Universidade Federal do Paraná, for providing meteorological data; Augusto Ferrari, from the Departamento de Zoologia, Universidade Federal do Rio Grande do Sul, for drawing the map; David Breth and Jordan Metcalf, KSU, for helping to measure and estimate insect numbers; and to the Conselho Nacional de Desenvolvimento Científico e Tecnológico $(\mathrm{CNPq})$ for grants to the authors.

\section{References}

Ainslie, C.N. 1938. Swarms of the common pentatomid Thyanta custator (F.), in Iowa. J. Econ. Entomol. 31: 130.

Brues, C.T. 1926. Remarkable abundance of a cistelid beetle, with observations on other aggregations of insects. Am. Naturalist 60: $526-545$.

Drake, V.A. 1984. The vertical distribution of micro-insects migrating in the nocturnal boundary layer. Boundary-Layer Met. 28: 353-374

Drake, V.A. \& A.G. Gatehouse. 1995. Insect migration: Tracking resources through space and time. Cambridge University Press, Cambridge, 478p.

Drake, V.A., A.G. Gatehouse \& R.A. Farrow. 1995. Insect migration: A holistic conceptual model, p.427-457. In V.A. Drake \& A.G. Gatehouse (eds.), Insect migration: Tracking resources through space and time. Cambridge University Press, Cambridge, 478p.

Drake, V.A., K.F. Helm, J.L. Readshaw \& D.G. Reid. 1981. Insect migration across Bass Strait during spring: A radar study. Bull. Ent. Res. 71: 449-466.

Drake, V.A. \& R.A. Farrow. 1988. The influence of atmospheric structure and motions on insect migration. Annu. Rev. Entomol. 33: $183-210$.

Drake, V.A. \& R.A. Farrow. 1989. The aerial plankton and atmospheric convergence. Trends Ecol. Evol. 4: 381-385.

Freeman, J.A. 1938. Composition of the aerial insect fauna up to 300 feet. Nature 142: 153-154.

Gatehouse, A.G. 1997. Behavior and ecological genetics of windborne migration by insects. Annu. Rev. Entomol. 42: 475-502.

Grazia-Vieira, J. 1972. O gênero Mayrinia Horvath, 1925 (Heteroptera, Pentatomidae, Pentatomini). Rev. Per. Entom. 15: $117-124$

Hardy, A.C. \& L. Cheng. 1986. Studies in the distribution of insects by aerial currents. III. Insect drift over the sea. Ecol. Entomol. 11: 283-290.

Hardy, A.C. \& P.S. Milne. 1937. Insect drift over the North Sea. Nature 139: 510-511.
Hardy, A.C. \& P.S. Milne. 1938. Aerial drift of insects. Nature 141: 602-603.

Holland, R.A., M. Wikelski \& D.S. Wilcove. 2006. How and why do insects migrate? Science 313: 794-796.

Johnson, C.G. 1969. Migration and dispersion of insects by flight. Methuen, London, 763p.

Leston, D. 1957. Spread potential and the colonization of islands. Syst. Zool. 6: 41-46.

Link, D. \& J. Grazia. 1987. Pentatomídeos da região central do Rio Grande do Sul (Heteroptera). An. Soc. Entomol. Bras. 16: $115-129$

McPherson, J.E. 1982. The Pentatomoidea (Hemiptera) of Northeastern North America with emphasis on the fauna of Illinois. Southern Illinois University Press, Carbondale and Edwardsville, IL, USA, 240p.

Myers, J.G. 1926. Heteroptera in ocean drift. Psyche 33: 110-115.

Needham, J.G. 1900. Insect drift on the shore of Lake Michigan. Occasional Mem. Chicago Entomol. Soc. 1: 19-26.

Needham, J.G. 1904. Beetle drift in Lake Michigan. Can. Entomol. 36: 294-296.

Needham, J.G. 1917. The insect drift of lake shores. Can. Entomol. 49: 129-137.

Panizzi, A.R. \& J.G. Smith. 1976. Ocorrência de Pentatomidae em soja no Paraná durante 1973/74. Biológico 62: 173-176.

Parshley, H.M. 1917. Insects in ocean drift. I. Hemiptera Heteroptera. Can. Entomol. 49: 45-48.

Pathak, S.C. 1998. Insect trappings in Arabian Sea with special reference to west coast of India. Indian J. Marine Sci. 27: 482-485.

Pathak, S.C., V. Kulshrestha, A.K. Choubey \& A.H. Parulekar. 1999. Insect drift over the northern Arabian sea in early summer. J. Biosci. 24: 233-240.

Russell, R.W. \& J.W. Wilson. 2001. Spatial dispersion of aerial plankton over east-central Florida: Aeolian transport and coastline concentrations. Int. J. Remote Sensing 22: 2071-2082.

Severin, C. 1937. Unusual abundance of Thyanta custator (Fabr.) in South Dakota. J. Econ. Entomol. 30: 210.

Schaefer, C.W. 2004. Leston's spread potential and taxon size, p.1-6. In G.T. Gujar (ed.), Contemporary trends in insect science. New Delhi, Campus, 424p.

Schmidt, L.S. \& A. Barcellos. 2007. Abundância e riqueza de espécies de Heteroptera-Hemiptera do Parque Estadual do Turvo, Sul do Brasil: Pentatomoidea. Iheringia, Série Zoologia 97: 73-79.

Torre Bueno, J.R. 1915. Heteroptera in beach drift. Entomol. News 26: $274-279$.

Wilbur, D.A. 1939. Mass flights of the pentatomid Thyanta custator (Fabr.) in Kansas. J. Kansas Ent. Soc. 12: 77-80.

Received 16/II/07. Accepted 01/IV/08. 